\title{
EL PARLAMENTO EUROPEO: NOTAS SOBRE LA REPRESENTACIÓN POLÍTICA Y LOS SISTEMAS ELECTORALES
}

\author{
M.․ ISABEL ÁLVAREZ VÉLEZ \\ M. FUENCISLA ALCÓN YUSTAS
}




\section{SUMARIO}

1. PAUTAS PARA UNA REPRESENTACIÓN POLITICA BASADA EN LA UNIFORMIDAD ELECTORAL. 2. EL DERECHO DE SUFRAGIO Y LA CARACTERIZACIÓN DEL MANDATO PARLAMENTARIO. 3. EL SISTEMA ELECTORAL PARA LA ELECCIÓN DE LOS PARLAMENTARIOS EUROPEOS EN LOS ESTADOS DE LA UNIÓN. 


\title{
EL PARLAMENTO EUROPEO: NOTAS SOBRE LA REPRESENTACIÓN POLÍTICA Y LOS SISTEMAS ELECTORALES
}

POR

\author{
M.․ ISABEL ÁLVAREZ VÉLEZ \\ Prof. Propia Agregada de Derecho Constitucional \\ Universidad Pontificia de Comillas \\ M. FUENCISLA ALCÓN YUSTAS \\ Prof. Propia Adjunta de Derecho Constitucional \\ Universidad Pontificia de Comillas
}

\section{PAUTAS PARA UNA REPRESENTACIÓN POLITICA BASADA EN LA UNIFORMIDAD ELECTORAL}

Desde los inicios de la construcción europea, los fundadores de la Comunidad pensaron en la creación de una Asamblea que representase a los ciudadanos de los Estados miembros. La histórica Declaración de Robert Schuman, Ministro francés de Asuntos Exteriores, el 9 de mayo de 1950, encerraba ya la simiente de una Europa no sólo unida por razones económicas, sino cimentada en bases políticas: "La puesta en común de las producciones del carbón y del acero asegurará inmediatamente el establecimiento de bases comunes de desarrollo económico, primera etapa de la federación europea, y cambiará el des- 
tino de estas regiones mucho tiempo consagradas a la fabricación de armas de guerra de las cuales han sido las más constantes víctimas" 1.

Tras la aceptación por parte de Alemania, Bélgica, Italia, Luxemburgo y Países Bajos de la propuesta francesa, no hubo dificultades para el proceso que desembocaría en la firma del Tratado de París ${ }^{2}$. Los primeros obstáculos para el desarrollo de los objetivos políticos y económicos propuestos, se debieron al fracaso de proyecto de Comunidad Económica de Defensa (CED), que el Parlamento francés se negó a ratificar. El proyecto del Tratado CED pretendía establecer un ejército europeo, pero la idea levantó una fuerte polémica en Francia. Con el fin de pacificar los ánimos, sin abandonar el propósito de profundizar en la unión y colaboración europea, Italia propuso la creación de una Comunidad Política Europea (CPE), fundamentada en el artículo 38 del proyecto de Tratado de la CED, que preveía el estudio de una futura estructura federal de Europa. Señala MANGAS MARTín que las competencias de la CPE serían «en materia de relaciones exteriores la coordinación de las políticas económicas y el establecimiento de un mercado común fundado en la libre circulación de personas, bienes y capitales, el cual absorbería gradualmente a la CECA y a la CED» ${ }^{3}$. Sin embargo, la Asamblea francesa rechazó la ratificación en una virulenta sesión parlamentaria, el 30 de agosto de 1954.

La crisis de la incipiente Comunidad Europea fue "pronto superada", como señala TRUYOL Y SERRA, gracias al impulso de Bélgica, Luxemburgo y Países Bajos, que presentaron a las instituciones de la CECA un Memorándum que manifestaba que "había llegado el momento de franquear una nueva etapa en el camino de la integración europea" " Además, en el documento se afirmaba que, en opinión de

1 La Declaración de Robert Schuman se produjo sólo cinco años después del fin de los horrores vividos en el corazón de Europa durante la Segunda Guerra Mundial. La Declaración fue elaborada por Jean Monnet, Comisario del Plan de Modernización y Equipamiento del Gobierno francés, fue primer Presidente de la Alta Autoridad de la CECA, y en 1955 fundó el Comité de Acción para los Estados Unidos de Europa. El texto de la Declaración está tomado de: TRUYOL Y SERRA, A., La integración europea, pág. 104

2 El Tratado de París, firmado el 18 de abril de 1951, constituyó la Comunidad Europea del Carbón y del Acero (CECA). Por primera vez, seis Estados Europeos transferian parte de sus derechos soberanos a una "Alta Autoridad común": «Por el presente Tratado las Altas Partes Contratantes instituyen entre ellas una Comunidad europea del carbón y del acero, fundada sobre un mercado común, objetivos comunes e instituciones comunes" (art. 1..$^{\text {TCECA). }}$

3 Mangas Martin, A., "Cuestiones históricas y generales", en MANGas MarTín, A. y LIÑÁN NOGUERAS, D.J., Instituciones y Derecho de la Unión Europea, pág. 9. TruYOl y SERRA, A.; op. cit, pág. 37. 
los Gobiernos de los Estados firmantes, la integración «debería ser realizada primero en el campo económicon. El resultado de esta iniciativa fue la reunión de Messina de junio de 1955, que dio lugar a la firma de los Tratados de Roma, el 25 de marzo de 19575.

La inviabilidad política de la CED y de la CPE, dieron al traste con las esperanzas de los europeístas convencidos, aquellos que perseguían, más allá de la unión económica, una unión integral cimentada en una estructura confederal o federal. No obstante, los Tratados de Roma, aunque limitaron los objetivos inmediatos de las organizaciones creadas al ámbito económico, no abandonaron los deseos de integración política, sólo los relegaron; la voluntad de una unión política se mantuvo en el texto de los Tratados. Por ello, al articular las instituciones de las Comunidades se pensó en la creación de una Asamblea que representara a los pueblos de los Estados integrantes ${ }^{6}$. Así lo estableció el artículo 137 del Tratado Constitutivo de la Comunidad Económica Europea (TCEE) 7: "La Asamblea compuesta por representantes de los pueblos de los Estados reunidos en la Comunidad, ejerce los poderes de deliberación y de control que se le atribuyen por el presente tratado". Además, aunque se establecía que la Asamblea estaría compuesta por "delegados que los Parlamentos designarán entre sus miembros según el procedimiento fijado por cada Estado miembro", se preveía también hacer efectivo el principio democrático, por lo que se encomendaba a la Asamblea la elaboración de uproyectos encaminados a permitir la elección por sufragio universal directo según un procedimiento uniforme, en todos los Estados miembros" (art. $138.1 \mathrm{y}$ 3 TCEE).

La actividad del Parlamento se lleva a cabo entre tres ciudades de distintos Estados miembros, separación que tiene raíces históricas y de naturaleza simbólica ${ }^{8}$. Pero el Tratado de Amsterdam, que incluyó la

5 Entre los artífices de los Tratados de Roma, que establecieron la Comunidad Económica Europea (CEE) y la Comunidad Europea de la Energía Atómica (Euratom o CEEA), podemos destacar al jurista alemán Walter Hallstein y al político belga Paul-Henri Spaak.

6 En los Tratados constitutivos de la Comunidad se utilizaba el término Asamblea, pero, por la Resolución de marzo de 1962 decidió autodenominarse Parlamento Europeo (PE). A pesar de que éste ha sido el término utilizado, formalmente esta denominación no se incluyó en los Tratados hasta el Acta Única Europea de 1986.

7 Nos referimos a la versión original del Tratado relativo a la creación de la Comunidad Económica Europea, hecho en Roma el 25 de marzo de 1957.

8 El Tratado de París situó a los órganos de la CECA en Luxemburgo, el Tratado de Roma instaló en Bruselas la mayor parte de las instituciones de la CEE y 
aprobación del Protocolo sobre la fijación de las sedes de las Instituciones $y$ de determinados organismos y servicios de las Comunidades Europeas y de Europol, formalizó la distribución que existía de hecho de los lugares de trabajo del Parlamento. Así establece el artículo único, apartado a) de este Protocolo: "El Parlamento Europeo tendrá su sede en Estrasburgo, donde se celebrarán los doce períodos parciales de sesiones plenarias mensuales, incluida la sesión presupuestaria. Los periodos parciales de sesiones plenarias adicionales se celebrarán en Bruselas. Las Comisiones del Parlamento Europeo se reunirán en Bruselas. La Secretaría General del Parlamento Europeo y sus servicios seguirán instalados en Luxemburgo".

Hasta 1979 la elección de los Diputados europeos se realizaba por los Parlamentos nacionales, por lo que constituía una elección de segundo grado, resultando obligatorio el doble mandato ${ }^{9}$. La duración del mandato europeo quedaba supeditada a la permanencia en el Parlamento nacional del Diputado designado. Fue en la Conferencia de la cumbre celebrada en París, los días 9 y 10 de diciembre de 1974, cuando se decidió que a partir de 1978 las elecciones al Parlamento Europeo serían directas. En virtud de esta decisión, y a tenor del proyecto presentado en enero de 1975 por el propio Parlamento, se acordó por el Consejo Europeo, de 12 y 13 de julio de 1976, dictar la normativa necesaria para que se hicieran realidad las previsiones de los Tratados fundacionales, relativas a las elecciones por sufragio universal directo. En Bruselas, el 20 de septiembre de 1976 el Consejo adoptó la Decisión

la CEEA, y el Parlamento se emplazó en Estrasburgo como símbolo de la reconciliación franco-alemana.

9 Este procedimiento, la elección de representantes europeos por los Parlamentos nacionales, desechado a partir de 1979, ha sido, sin embargo, utilizado para la representación en el Parlamento Europeo de los Estados que se han ido adhiriendo a la Unión, tras las sucesivas ampliaciones. Así, el Acta relativa a las condiciones de adhesión de España y a las adaptaciones de los Tratados, incorporada al Tratado de Adhesión a las Comunidades Europeas, de 12 de junio de 1985, establecía que hasta la elección por sufragio universal de los Diputados europeos, éstos serían designados por las Cortes Generales. En virtud de dicha normativa, las mesas del Congreso y del Senado se reunieron en sesión conjunta para acordar el procedimiento de designación de los Diputados europeos, acordando que los sesenta miembros podrían ser indistintamente Senadores o Diputados de las Cortes Generales y acordando la distribución entre los Grupos Parlamentarios, en función de su importancia política en cada Cámara. Vid. Elecciones al Parlamento Europeo (Documentación preparada para la tramitación del Proyecto de Ley de modificación de la Ley Orgánica 5/1985, de 19 de junio, de Régimen Electoral General, para la regulación de las Elecciones al Parlamento Europeo); BOCG-Congreso, Serie A, núm. 23, de 4 de febrero de 1987; Documentación núm. 54, febrero 1987; págs. 359-369. 
y el Acta relativa a la elección por sufragio universal de los representantes del Parlamento Europeo. El objeto de la Decisión es la ejecución de una de las disposiciones de los Tratados, mientras que el Acta aneja contiene las normas aplicables a las elecciones ${ }^{10}$. Este importante acuerdo de las instituciones comunitarias otorgó al Parlamento europeo una nueva legitimidad democrática, abriendo el futuro de la Cámara, que ha ido asumiendo mayores competencias y acrecentado su protagonismo político. La reforma convirtió al Parlamento Europeo en la única Asamblea del mundo integrada por representantes elegidos directamente por los pueblos de diferentes Estados.

La naturaleza del Parlamento Europeo ha quedado reconocida en el artículo 189 TCE 11, que pone de relieve que no representa al pueblo de la Unión Europea, que, como tal, carece de reconocimiento jurídico en los Tratados. Dicho precepto considera que el Parlamento está compuesto «por representantes de los pueblos de los Estados reunidos en la Comunidad". Por ello, la doctrina entiende que el Parlamento no representa al pueblo de la Unión, porque tal pueblo no existe ${ }^{12}$. Sin embargo, los Diputados europeos gozan de legitimidad democrática y no están vinculados a los Gobiernos de los Estados miembros. El artículo 4.1 del Acta de 1976 considera que los representantes en el Parlamento Europeo «no podrán quedar vinculados por instrucciones ni recibir mandato imperativo alguno", y en el mismo sentido el artículo 2 del Reglamento del Parlamento Europeo (RPE) proclama la indepen-

10 Afirma Aracell Mangas que la Decisión de 20 de septiembre de 1976 es una "Decisión sui generis, no enmarcable en la tipología de fuentes prevista en el art. 149.4 TCE». En cuanto al Acta «es un acuerdo internacional sujeto a la prestación de consentimiento por cada Estado miembro; constituye Derecho originario, pues no sólo ejecuta las previsiones de los Tratados, sino que también modifica algunas disposiciones de los mismos...": MANGAS MARTí, A., op. cit.; pág. 80.

11 Tratado Constitutivo de la Comunidad Europea, según las modificaciones establecidas hasta la fecha. La numeración es la contenida en el artículo 12 del Tratado de Amsterdam.

12 LaVILla Rubira; J. J., "La posición institucional del Parlamento Europeo", Revista de las Cortes Generales, núm. 9, 1986, pág. 16. Entre otros autores, también puede consultarse la opinión de Ángel RodRíguez: «aunque los miembros del Parlamento Europeo son los únicos integrantes de una institución comunitaria elegidos por sufragio directo de los ciudadanos, no puede afirmarse que el PE represente al pueblo de la Comunidad, que, jurídicamente no existe como tal.» (...). "La voluntad del Parlamento Europeo no puede imputarse a un pueblo al que no representa y que jurídicamente no existe. Si entendemos que forma parte de la naturaleza parlamentaria su condición de órgano representativo, es preciso concluir, por tanto, que el $P E$, a pesar de su denominación, no tiene, en realidad, naturaleza parlamentarian: RODRÍGUEZ, A., "Unión Europea: organización institucional", en BALAGUER CALLEJÓN, F. (coord): Derecho Constitucional, Vol. I, pág. 189. 
dencia de los Diputados y también «que no están sujetos a instrucciones ni a mandato imperativo alguno".

Por ello, aunque el pueblo de los Estados de la Unión no constituya un cuerpo electoral único, la legitimación democrática del Parlamento Europeo quedó garantizada, mediante la constitución de una Cámara plurinacional en la que los Diputados no representan a los Estados nacionales, sino a las tendencias políticas, las ideologías, o los ideales, de los ciudadanos. A través del principio de democracia representativa y del sistema de partidos, de los que gozan todos los Estados de la Unión, en donde el pluralismo es un requisito para la adhesión, los Diputados del Parlamento Europeo son representantes directos de los ciudadanos. Por ello, los Diputados se agrupan por afinidad política e ideológica, de modo que los ocho grupos políticos que actualmente constituyen el Parlamento, integran a más de cien formaciones políticas de todos los Estados de la Unión. La vinculación ideológica, y no territorial, de los Diputados europeos contribuye a la cooperación política entre partidos, y otras formaciones europeas, unificando posturas y estrategias parlamentarias, por encima de los intereses nacionales. Incluso el artículo 191 TCE recoge estos principios al afirmar que "los partidos políticos a escala europea constituyen un importante factor para la integración" 13.

La Decisión y el Acta de 20 de septiembre de 1976, tras la ratificación por todos los Estados miembros, entraron en vigor el 1 de julio de 1978. Las primeras elecciones por sufragio universal se realizaron el 7 y 10 de junio de 1979. En esta fecha el Parlamento estaba compuesto por cuatrocientos diez Diputados, e integraban la Comunidad nueve Estados: Alemania, Bélgica, Dinamarca, Francia, Irlanda, Italia, Luxemburgo, Países Bajos y Reino Unido. El 1 de enero de 1981, tras la adhesión de Grecia, el Parlamento griego designó los veinticuatro representantes en el Parlamento Europeo, que en 1981 fueron sustituidos por Diputados elegidos por sufragio universal directo. Las segundas elecciones directas se llevaron a cabo del 14 al 17 de junio de 1984, en las que se eligió un Parlamento de cuatrocientos treinta y cuatro Diputados. El 1 de enero de 1986, el número de parlamentarios europeos se incrementó con los sesenta Diputados designados por las Cortes Generales españolas y los veinticuatro designados por la Cámara portuguesa, por lo que el número total pasó a ser de quinientos dieciocho. Las terceras elecciones se celebraron del 15 al 18 de junio de 1989.

Este precepto fue introducido por el Tratado de Maastricht. 
En 1992, el Consejo Europeo de Edimburgo, reunido los días 11 y 12 de diciembre, modificó la composición del Parlamento, para adecuar la representación a la unificación alemana y a las perspectivas previstas de ampliación. Por Decisión del Consejo de 1 de febrero de 1993 "por la que se modifica el Acta relativa a la elección de los representantes del Parlamento Europeo por sufragio universal directo, anejo a la decisión del Consejo de 20 de septiembre de 1976" 14, el número de Diputados europeos pasó de quinientos dieciocho a quinientos sesenta y siete, aplicándose un nuevo modelo de reparto que afectó a nueve Estados constitutivos de la Unión. Esta distribución de escaños se aplicó en las elecciones de 9 y 12 de junio de 1994.

La adhesión de Austria, Finlandia y Suecia, modificó nuevamente la composición del Parlamento, que ha pasado a estar integrado por seiscientos veintiséis Diputados. Éste fue el número de parlamentarios elegidos en las últimas elecciones, que se llevaron a cabo entre el $10 \mathrm{y}$ el 13 de junio de 1999, mandato parlamentario que finalizará en el año 2004, dado que tiene una duración de cinco años, a tenor de lo establecido en el artículo 190.3 TCEE.

Por otra parte, ante las previsiones de nuevas ampliaciones de la Unión, y con el fin de evitar un aumento indefinido del número de miembros del Parlamento, la propia Cámara recomendó establecer, para el futuro, un número máximo de setecientos Diputados. La petición fue aceptada, por lo que se incluyó en el Tratado de Amsterdam, modificándose el artículo 189 TCEE 15.

14 DOCE L 33 de 9 de febrero de 1993.

15 La inclusión del apartado 2 en el artículo 190 preveía futuras modificaciones en la redistribución del número de Diputados, en función de la ampliación de la Unión. En este sentido, la LO 3/2001 de 6 de noviembre (BOE núm. 267 de 7 de noviembre) por la que se autoriza la ratificación por España del Tratado de Niza firmado en Niza el día 26 de febrero de 2001 por el que se modifican el Tratado de la Unión Europea, los Tratados Constitutivos de las Comunidades Europeas y determinados actos conexos, cambia el número de representantes del Parlamento Europeo a partir del 1 de enero de 2004 y con efectos desde el inicio de la legislatura 20042009. A partir de esta fecha, el número de representantes elegidos en cada Estado miembro será el siguiente: Alemania, noventa y nueve; Austria, diecisiete; Bélgica, veintidós; Dinamarca, trece; España, cincuenta; Finlandia, trece; Francia, setenta y dos; Grecia, veintidós; Irlanda, doce; Italia, setenta y dos; Luxemburgo, seis; Países Bajos, veinticinco; Portugal, veintidós; Reino Unido, setenta y dos; y Suecia, dieciocho. A los representantes de los actuales Estados miembros deberá añadirse en las fechas indicadas el número de representantes de los nuevos Estados miembros que se derive de los Tratados de adhesión firmados a más tardar el 1 de enero de 2004. En caso de que el número total de los miembros sea inferior a setecientos treinta y dos se aplicará una corrección proporcional, conforme a los principios establecidos 
Esta representación carece de proporcionalidad con la población de los Estados. Como ocurre, con frecuencia, con los repartos de escaños en las elecciones nacionales, existen desigualdades en el momento de la transformación de votos en escaños. En el caso del Parlamento Europeo los Estados de menor población están sobrerrepresentados. No obstante, la justificación de esta distribución de escaños encuentra mayores cimientos en lo que se refiere al Parlamento Europeo, que en el reparto de los representantes parlamentarios en el ámbito nacional de algunos Estados miembros ${ }^{16}$. La "desigualdad" se justifica por la necesidad de que los países pequeños tengan en la Cámara europea un cierto peso político, de tal forma que, por encima del número de habitantes, los criterios de distribución de escaños deben permitir la participación activa en las tareas parlamentarias a todos los Estados miembros. En caso contrario las Estados grandes monopolizarían las tareas parlamentarias e impondrían su voluntad en las votaciones ${ }^{17}$.

Por otra parte, el artículo 190.4 TCE establece que las elecciones por sufragio universal de los Diputados europeos se llevarán a cabo "de acuerdo con un procedimiento uniforme en todos los Estados miembros", pero aún no se ha llegado a establecer una normativa que fuera aceptada por todos los Estados ${ }^{18}$. El Parlamento Europeo, en cumplimiento de las disposiciones del TCE, ha insistido, desde que se adoptó el sufragio universal, en el desarrollo de diferentes proyectos que regulasen un procedimiento electoral uniforme para todos los Estados miembros, pero sin que encontrasen unanimidad en el Consejo, aunque las posturas se han aproximado y es muy probable que el acuerdo llegue antes de las elecciones de 200419.

en el propio TCEE, mediante Decisión del Consejo. De forma transitoria y durante el periodo de aplicación de dicha Decisión, el número total de representantes podrá superar a los setecientos treinta y dos.

16 Aproximadamente, ochocientos mil alemanes, seiscientos mil españoles o sesenta mil luxemburgueses, están representados por un Diputado en el Parlamento Europeo

17 En opinión contraria ARACELI MANGAS mantiene que «el reparto tiene en cuenta una proporcionalidad muy poco acorde con la población de cada Estado miembro; esto pone en duda su verdadera representación popular o democrática y muestra hasta que punto el elemento internacional, la representación de cada Estado, está presente e influye en lo más aparentemente comunitario como debería ser el PEn: Vid. MANGAS MARTín, A., op. cit.; pág. 81

18 La falta de un compromiso se debió, entre otras razones, a que Reino Unido mantenía el sistema mayoritario de elección, frente al resto de las legislaciones nacionales que establecen un sistema proporcional.

19 El artículo 190.4 TCE en su párrafo segundo afirma que «el Consejo establecerá por unanimidad, previo dictamen conforme del Parlamento Europeo, que se 
El primer proyecto de relevancia fue aprobado en el Parlamento el 10 de marzo de 1982 por ciento cincuenta y ocho votos a favor, setenta y siete en contra y veintisiete abstenciones ${ }^{20}$. Se trataba del proyecto Seitlinger, una propuesta ambiciosa, en la que se proponía generalizar en los Estados miembros el método electoral D'Hondt, con circunscripciones plurinominales en las que se eligiera entre tres $y$ quince Diputados, sin umbrales mínimos para entrar en el recuento de votos. EI COREPER estudió la propuesta, que no pasó al Consejo.

Después de las elecciones de 1984, el Parlamento acordó la elaboración de un nuevo proyecto que desarrollara los principios exigidos para el establecimiento de un sistema electoral uniforme. Esta vez fue el Diputado Bocklet, el ponente del informe, miembro de la Comisión de Asuntos Políticos 21. Esta Comisión aprobó el proyecto el 28 de febrero de 1985, pero antes de que se sometiera a votación por el Pleno, la Comisión de Asuntos Jurídicos manifestó su opinión contraria a algunas de las propuestas, por lo que se creó un Grupo mixto que continuó los trabajos, sin que el resultado fuera positivo. Después de las elecciones de 1989, el Parlamento retomó la elaboración de un proyecto sobre el sistema electoral uniforme capaz de aunar la voluntad del Consejo. Fue designado ponente el Diputado De Gucht. La elaboración del informe, se desarrolló básicamente en un grupo de trabajo informal creado en el seno de la Comisión de Asuntos Institucionales, a lo largo de casi tres años 22 . Finalmente, el proyecto sufrió dos votaciones diferentes en el Parlamento. El acuerdo definitivo fue aprobado el 10 de marzo de 1993, por doscientos siete votos a favor, setenta y nueve en contra y diecinueve abstenciones, pero no contó con la aprobación del Consejo ${ }^{23}$.

Las experiencias anteriores habían dado lugar a que en el seno de la Cámara se implantara el convencimiento de que el concepto de "uniformidad" no debía entenderse como una identidad en la elección

pronunciará por mayoria de sus miembros, las disposiciones pertinentes y recomendará a los Estados miembros su adopción, de conformidad con sus respectivas normas constitucionales".

20 DO C 87/1982, pág. 61.

21 El proyecto Bocklet consideraba que el sistema electoral uniforme debería alcanzarse por etapas. Se mantenía el método electoral $D^{\prime} H o n d t$, pero se permitía que las legislaciones nacionales decidieran sobre la circunscripción única, o establecieran varias circunscripciones, así como acerca del umbral mínimo de votos, que en ningún caso podría ser superior al cinco por ciento. Ver informe Bocklet en Documento PE 132.437 de 17 de julio de 1986.

22 DO C 280/1991, de 28 de octubre, pág. 141.

23 DO C 115/1993, de 26 de abril, pág. 59. 
de los Diputados Europeos, puesto que resultaba inviable pretender igualar el procedimiento electoral en todos los Estados. Los criterios intentaban alcanzar consenso en los elementos esenciales del sistema electoral, pero respetando ciertas distinciones nacionales 24 . Estos criterios fueron recogidos en la Conferencia Intergubernamental, cuya apertura solemne tuvo lugar el 29 de marzo de 1996, y recogidos en el Tratado de Amsterdam, que modificó la redacción del artículo 190.4 TCE, con el fin de establecer una normativa menos rigurosa que permitiera alcanzar en el seno del Consejo el deseado acuerdo. Así, la redacción del citado precepto incluyó un inciso, de modo que se considera que el procedimiento electoral para la elección de los Diputados al Parlamento Europeo, puede ser uniforme o responder a "principios comunes a todos los Estados miembros".

El 5 de noviembre de 1997, el Presidente del Parlamento anunció que la Comisión de Asuntos Institucionales había sido autorizada a presentar un informe sobre la elaboración de un proyecto de procedimiento electoral uniforme, que seguiría las nuevas directrices. EI ponente designado fue el Diputado Gregorios Anastassopoulos, miembro de la Comisión de Asuntos Institucionales, que presentó su informe a los órganos de la Cámara ${ }^{25}$. El 15 de julio de 1998, el Parlamento Europeo aprobó una Resolución sobre la elaboración de un proyecto de procedimiento electoral fundado en principios comunes para la elección de los Diputados al Parlamento Europeo, basada en el informe del Diputado Anastassopoulos 26.

En su Resolución, el Parlamento Europeo propuso un proyecto de Acto del Consejo, integrado por diez artículos, en el que destacan los siguientes puntos:

El sufragio será universal, directo, libre, igual para todos y secreto. Los Diputados serán elegidos por votación de listas, según el sistema proporcional.

24 Los criterios contenidos en esta Resolución eran los siguientes: distribución de escaños por un sistema de representación proporcional, teniendo en cuenta los votos emitidos en todo el Estado miembro; listas electorales de ámbito nacional o para regiones o distritos electorales con varios candidatos; posibilidad de votos preferenciales; barrera mínima permitida entre tres y cinco por ciento; $y$, la autorización de que los Estados miembros previeran normativas específicas referentes a peculiaridades regionales, respetando el principio de representación proporcional.

25 Al informe de Anastassopoulos se adjuntó la propuesta de Resolución de Vires, sobre la misma materia que había sido remitida a la Comisión en octubre de 1996.

26 Resolución A4-0212/98, de 15 de julio. 
A partir de las elecciones del año 2004, cada Estado miembro constituirá circunscripciones territoriales sin que ello menoscabe el carácter proporcional del sistema electoral. Esta disposición no obligará a los Estados con menos de veinte millones de habitantes.

Para tener en cuenta la especificidad regional serán permitidas disposiciones especiales, siempre que no vayan en detrimento del principio de representación proporcional.

Podrá establecerse un umbral mínimo, en el ámbito nacional, para la atribución de escaños, pero no podrá ser superior al cinco por ciento de los votos emitidos.

Los Estados miembros podrán permitir el voto preferencial.

Incompatibilidad entre el mandato de Diputado Europeo y el mandado de Diputado de un Parlamento nacional.

Establecimiento por los Estados miembros de un límite en los gastos que los candidatos destinan a la campaña electoral.

A partir de las elecciones europeas del año 2009, el diez por ciento de los escaños del Parlamento se proveerán por votación de listas según un sistema proporcional, en el marco de una circunscripción única formada por el territorio de los Estados de la Unión Europea.

En un futuro próximo parece que se hará al fin viable la aprobación de un sistema electoral basado en criterios de uniformidad, que podría aplicarse a las próximas elecciones al Parlamento Europeo en el año 2004. Los avances en este terreno, aunque lentos, deben ser valorados positivamente, pues son muchas las dificultades que presenta la modificación legislativa de los procesos electorales, dada su complejidad técnica y los efectos en el sistema de representación.

\section{EL DERECHO DE SUFRAGIO Y LA CARACTERIZACIÓN DEL MANDATO PARLAMENTARIO}

El Tratado de Maastricht incluyó en el TCEE los artículos 17 a 22 referidos íntegramente a la "Ciudadanía de la Unión". El primero de dichos preceptos constituye una ciudadanía de la Unión, "complementaria y no sustitutiva de la ciudadania nacional" que ostentará todo ciudadano de un Estado miembro. Por otra parte, a la espera del reconocimiento jurídico-formal de un Código de derechos humanos por las instituciones europeas, la labor que realiza el Tribunal de Justi- 
cia de las Comunidades en defensa de los derechos humanos, encontró nuevo fundamento en la redacción del apartado 1 del artículo 6 del Tratado de la Unión (TUE), añadido por el Tratado de Amsterdam: "La unión se basa en los principios de libertad, democracia, respeto de los derechos humanos y de las libertades fundamentales y el Estado de Derecho, principios que son comunes a los Estados miembros" 27.

En éstos y otros preceptos del Derecho Comunitario, se perfilan los derechos del ciudadano europeo, y asi lo reconoce el apartado 2 del artículo 17 TCE: "Los ciudadanos de la Unión serán titulares de los derechos y sujetos de los deberes previstos en el presente Tratado". Y, en la materia que nos ocupa, recordemos que el artículo 190 TUE dispone que "los representantes en el Parlamento Europeo de los pueblos reunidos en la Comunidad serán elegidos por sufragio universal directo", por lo que se reconoce al derecho al sufragio activo y pasivo de los nacionales de los Estados miembros.

De tal modo, la noción de ciudadanía de la Unión, de conformidad con el artículo 19.2 TCE, representa que todos los ciudadanos de la Unión gozan del derecho de sufragio activo y pasivo en las elecciones al Parlamento Europeo, incluso aquellos que residan en un Estado miembro del que no sean nacionales ${ }^{28}$. El artículo 19.2 TCE prevé también que se elaboren disposiciones sobre modalidades del ejercicio de dichos derechos que el Consejo deberá adoptar, "por unanimidad, a propuesta de la Comisión y previa consulta al Parlamento Europeo»: El objeto de dichos preceptos consiste en suprimir el requisito de la nacionalidad para el ejercicio del derecho al sufragio activo y pasivo, lo que representa un paso destacado en el proceso de integración de los ciudadanos en la Unión ${ }^{29}$. No obstante, el artículo 19.2 TCE también ha

27 Considera Araceli MANGAS, que la expresión es reiterativa, pues el concepto de Estado de Derecho "engloba el respeto por el pluralismo, la voluntad popular, los derechos humanos y el respeto de la legalidad": MANGAS MARTín, A. "Estudio Preliminar", en Tratado de la Unión Europea, Tratados Constitutivos de las Comunidades Europeas y otros actos básicos de Derecho Comunitario, nota 14 , pág. 74.

28 El contenido del apartado 1 del artículo $19 \mathrm{CE}$ es similar al del apartado 2 , que estudiamos a nuestros propósitos, pero referido a los derechos de sufragio activo y pasivo a las elecciones municipales. Es sabido, que en virtud de lo dispuesto en el artículo 8. b). 1 TUE los nacionales de los Estados miembros de la Unión gozan del derecho de sufragio activo y pasivo en las elecciones municipales de los Estados en los que sean residentes.

29 El Acta de 1976 no resolvió el problema de la participación en las elecciones de los ciudadanos de la Unión residentes en un Estado miembro distinto del que sean nacionales, pero esta cuestión estuvo latente desde el primer momento en 
previsto el establecimiento de excepciones a la legislación comunitaria, "cuando lo justifiquen problemas especificos de un Estado miembro".

El desarrollo del artículo 19.2 TCE, se llevó a cabo a través de la Directiva 93/109, de 6 de diciembre ${ }^{30}$ que fijó las modalidades de ejercicio del derecho de sufragio activo y pasivo en las elecciones al Parlamento Europeo, de los ciudadanos de la Unión residentes en un Estado miembro del que no sean nacionales. Los requisitos para ser elector y elegible son los mismos que los exigidos a los nacionales del Estado de residencia, no obstante, la Directiva, conforme a las previsiones del artículo 19 TCE, recoge ciertas excepciones ${ }^{31}$. Asi, en los Estados en que el porcentaje de residentes extranjeros procedentes de la Unión Europea sea superior al veinte por ciento del electorado, se podrá ampliar el período de residencia para los ciudadanos que no sean nacionales de dicho Estado. Este ha sido el caso de Luxemburgo, Estado al que se ha concedido por el Consejo una serie de medidas de excepción, debido al elevado número de ciudadanos de otros Estados miembros de la Unión que residen en él. Por esta razón, se ha concedido el plazo mínimo de residencia de cinco años para ejercer el derecho de sufragio activo, un plazo de residencia de diez años para ser candidato a las elecciones y la prohibición de que sean mayoría los candidatos no luxemburgueses que puedan presentarse en una misma lista electoral ${ }^{32}$.

La aplicación de las disposiciones del TCE, al ampliar el derecho de sufragio a todos los ciudadanos europeos, se integra en la voluntad comunitaria de construir un concepto sólido de ciudadanía de la Unión, pues favorece la integración de los ciudadanos de la Unión en el Estado miembro de residencia. En último término, se trata de ahondar en las libertades de circulación y de residencia en el territorio de la Unión, que están recogidas en el artículo 18 TCE y que forman parte del ideario fundacional de las Comunidades. También constituye un avance en la aplicación del principio de igualdad y no discriminación entre los ciudadanos de la Unión 33.

el ánimo de los Diputados europeos. Vid. SantaOlalla LóPEz, F.; Elección en España del Parlamento Europeo; págs. 46 y 47.

30 DO L 329 de 30 de diciembre de 1993, págs. 34-38.

31 Se trata de disposiciones de excepción y no sólo temporales. Es decir para que se mantengan es necesario que subsistan las circunstancias que aconsejan su aprobación.

32 Los electores comunitarios no luxemburgueses, que por residir fuera de su territorio carezcan del derecho de sufragio en su Estado nacional, están exentos de la obligación de plazo mínimo de residencia.

33 El principio de igualdad y no discriminación se proclama en diferentes preceptos de los Tratados: art. 169 TCECA, 12, 13, 39, 40, 137 y 141 TCE. 
Por otra parte, la falta de un sistema electoral uniforme para todos los Estados miembros de la Unión, conlleva que la normativa comunitaria haya establecido sólo las bases de la elección, sobre todo en lo relativo al derecho de sufragio universal directo y al derecho de voto de los ciudadanos europeos en cualquiera de los Estados miembros, dejando en manos de los legisladores nacionales, la regulación del modelo electoral, la capacidad y los requisitos para el ejercicio del derecho de sufragio, las modalidades de voto, la presentación de candidaturas y los procedimientos y recursos electorales ${ }^{34}$. Por ello, junto al deseo de profundizar en las garantías del ejercicio del sufragio y en los principios que nutren al Parlamento Europeo como «pilar democrático", persiste la vocación de unificar el sistema electoral de los Estados miembros, pues en determinados aspectos destacados de los sistemas electorales en vigor, las desigualdades entre las legislaciones nacionales son notables.

La edad exigida para el ejercicio del derecho activo a las elecciones al Parlamento Europeo es en todos los Estados miembros de la Unión de dieciocho años ${ }^{35}$. No ocurre lo mismo con el ejercicio del sufragio pasivo, pues aún subsisten importantes diferencias entre las legislaciones de los Estados miembros. En siete Estados, la edad fijada para el ejercicio de sufragio pasivo es la misma que para ejercer el derecho de sufragio activo, dieciocho años. Estos Estados son: Alemania, Dinamarca, España, Finlandia, Países Bajos, Portugal y Suecia 36. En Austria, la edad exigida para el derecho de voto pasivo es de diecinueve años 37; veintiuno en Bélgica, Grecia, Irlanda, Luxemburgo y

34 La convergencia de las normativas comunitaria y nacionales se pone de manifiesto en el artículo 7.2 del Acta de 1976 que establece: "Hasta la entrada en vigor de un procedimiento electoral uniforme, y sin perjuicio de las demás disposiciones de la presente Acta, el procedimiento electoral se regirá, en cada Estado miembro, por las disposiciones nacionales».

35 El algunos Estados miembros el establecimiento del derecho al sufragio activo a los dieciocho años es reciente. En Bélgica la Ley de 1978 rebajó la edad electoral para el ejercicio del derecho al sufragio activo a los dieciocho años, pues con anterioridad estaba fijada a los veintiuno. En España, el artículo 2.1 de la LOTC afirma que el «derecho de sufragio corresponde a los españoles mayores de edad...".

36 Artículo 38 de la Ley Fundamental de Bonn; articulo 29 de la Ley Constitucional Austriaca; artículo 12 de la Constitución española; artículo 30 de la Constitución danesa; artículos 6 y 7 de la Ley Orgánica del Parlamento finlandés; artículo 56 de la Constitución de los Países Bajos; artículo 49 de la Constitución portuguesa y artículo 2 del Capítulo Tercero de la Ley Constitucional sueca.

37 La entrada de Austria en la Unión llevó consigo la reforma de la Ley Constitucional, de modo que se incluyeron los artículos del 23a al 23 e en la Parte Primera del texto, en un nuevo apartado B dedicado a «la Unión Europea». El apar- 
Reino Unido ${ }^{38}$; veintitrés en Francia; $y$, veinticinco en Italia ${ }^{39}$. Las diferencias son, por tanto, notables, lo que resulta sorprendente en países que han profundizado en aspectos esenciales del sistema democrático, especialmente en la ampliación y reconocimiento de los derechos fundamentales de la persona.

La normativa comunitaria establece el criterio de que en todos los Estados miembros sea necesario, para ser candidato poseer la nacionalidad de un Estado miembro de la Unión Europea y reunir los requisitos de residencia previstos en la ley. Pero, la diversidad de legislaciones nacionales hace que el concepto de residencia no sea el mismo en todos los Estados, por lo que cambian las condiciones para el ejercicio del sufragio. Desigualdades que pretende paliar el artículo 5 de la Directiva 93/109, que señala usi, para ser electores o elegibles, los nacionales del Estado miembro de residencia deben residir desde un período mínimo en el territorio electoral se presumirá que cumplen este requisito los electores y elegibles comunitarios que hayan residido durante un periodo equivalente en otros Estados miembros». No obstante, el precepto señalado incluye un inciso permitiendo ciertas peculiaridades, en lo que se refiere al cumplimiento del período de residencia: "Esta disposición se aplicará sin perjuicio de las condiciones específicas relativas al período de residencia en una circunscripción electoral o entidad local determinada".

La Directiva 93/109 exige, además de la inscripción del ciudadano comunitario, en el Estado de residencia, una declaración formal de que ejercerá su derecho de voto únicamente en el Estado miembro de residencia. El mismo requisito se exige para la presentación de candidatura, que debe ir acompañada de una declaración en la que se indique, que el ciudadano comunitario no es simultáneamente candidato en otro Estado miembro. Además, hay que tener en cuenta que cada candidato comunitario deberá reunir los mismos requisitos exigidos al candidato nacional para el ejercicio de sufragio.

tado 1 del artículo 23a concede derecho de sufragio activo para las elecciones al Parlamento Europeo a aquellos austríacos que hayan alcanzado la edad de 18 años cumplidos el 1 de enero del año electoral. El apartado 3 del mismo artículo considera elegibles a todos los austríacos que hayan alcanzado el 1 de enero del año electoral la edad de 19 años cumplidos.

38 Vid. artículo 64 de la Constitución belga, artículo 51 de la Constitución griega, artículo 16.1. 1. ${ }^{\mathrm{a}}$ y $2 . \stackrel{\mathrm{a}}{\mathrm{a}}$ de la Constitución irlandesa, artículo 52 de la Constitución luxemburguesa.

39 Artículo 56 y 58 de la Constitución italiana. 
Todas estas medidas persiguen la plenitud del ejercicio de los derechos del ciudadano europeo, pero también prevén posibles abusos o fraudes de ley, para que la residencia en un Estado miembro no sea utilizada para participar en unas elecciones que le estarían vedadas en el Estado del que el ciudadano sea nacional. Por ello, el artículo 6 de la Directiva que estudiamos, dispone que "todo ciudadano de la Unión que resida en un Estado miembro sin tener en cuenta su nacionalidad y que, por resolución individual en materia civil o penal, haya sido desposeído del derecho de sufragio pasivo en virtud, bien de la legislación del Estado miembro de residencia, bien de la del Estado miembro de origen, quedará desposeído del ejercicio de ese derecho en el Estado miembro de residencia en las elecciones al Parlamento Europeo". De modo semejante el artículo 7 de esta norma comunitaria, establece que «El Estado miembro de residencia podrá asegurarse de que los ciudadanos de la Unión que hayan manifestado la voluntad de ejercer en ese Estado su derecho de sufragio activo no hayan sido desposeídos de dicho derecho en el Estado miembro de origen por resolución individual en materia civil o penal» 40 .

Con el fin de asegurar la aplicación efectiva de los anteriores preceptos, la Directiva ha previsto el intercambio de las informaciones interestatales necesarias para evitar el doble voto o la doble candidatura. También es obligación del Estado miembro de residencia informar al elector residente, nacional de otros Estados miembros, del curso que se haya dado a su solicitud de ejercicio del derecho de voto o de la presentación de candidatura. En caso de que las solicitudes fueran rechazadas, el ciudadano comunitario tendrá el derecho a utilizar los recursos establecidos en la legislación nacional del Estado de residencia.

Las legislaciones nacionales presentan determinadas diferencias en lo que respecta a las condiciones del ejercicio del derecho de sufragio a las elecciones al Parlamento Europeo cuando se reside en un Estado que no sea miembro de la Unión. Austria, Dinamarca, Irlanda, Portugal y los Paises Bajos sólo conceden el derecho de sufragio a aquellos ciudadanos que residan en Estados miembros de la Comunidad. Suecia, Luxemburgo, Bélgica, Francia, España, Grecia 41, Italia y

40 En España no está prevista en la Ley Orgánica 10/1995, de 23 de noviembre que aprueba el nuevo Código Penal la pena de suspensión del derecho de voto activo, lo que deja sin aplicación lo previsto en el artículo 3.1 a) de la Ley Orgánica 5/1985, de 19 de junio de Régimen Electoral General.

41 En Grecia los ciudadanos que residan fuera del territorio de la Unión pueden votar en las elecciones al Parlamento Europeo, pero han de hacerlo en un Estado miembro de la Unión o regresar a Grecia. 
Finlandia, conceden el derecho de voto a sus nacionales, sea cual sea el país de residencia. Alemania concede derecho de voto a todos sus ciudadanos residentes en un Estado que pertenezca al Consejo de Europa, o en cualquier otro país que no pertenezca a la Unión, siempre que residan en él desde un plazo no superior a diez años.

El Parlamento Europeo asume la verificación de las credenciales de los Diputados electos tal como señala el artículo 7.1 del Reglamento de la Cámara (RPE): "resolverá sobre la validez del mandato de cada uno de sus Diputados electos, así como sobre las impugnaciones que se hubieren presentado de acuerdo con lo dispuesto en el Acta de 20 de septiembre de 1976, salvo las fundadas en las leyes electorales nacionales". Es decir, el Parlamento Europeo goza de atribuciones para la verificación de las credenciales de los Diputados y para la resolución de las impugnaciones fundadas en la normativa comunitaria, mientras que los recursos contencioso-electorales, basados en la legislación de los Estados miembros, constituye competencia de los órganos nacionales de acuerdo con lo dispuesto en la legislación correspondiente. Pero, incluso, cuando se haya iniciado en el ámbito nacional, «un procedimiento que pudiera conducir a la anulación del mandato de un Diputado", el Presidente del Parlamento "pedirá que se le informe periódicamente sobre el estado del procedimiento" y encargará "del seguimiento del asunto a la comisión competente, a propuesta de la cual podrá pronunciarse el Parlamento" (art. 7.4 RPE). No obstante, el buen funcionamiento de la Cámara y el respeto al mandato parlamentario obligan a que todo Diputado «ocupe su escaño en el Parlamento y en sus órganos con plenitud de derechos, aunque no se hubiera verificado su credencial o no se hubiera resuelto sobre una posible impugnación" (art.7.5 RPE).

Los Diputados europeos están sometidos a un régimen de incompatibilidades, establecido en una normativa que es también en parte comunitaria y en parte nacional. El Acta de 20 de septiembre de 1976 previó la compatibilidad de la calidad de representante en el Parlamento Europeo con la de miembro de un Parlamento nacional. Sin embargo, las leyes electorales belga, española y griega establecieron la incompatibilidad de ambos mandatos 42 .

42 A pesar de que la Ley holandesa de 13 de diciembre de 1978 que regula las elecciones al Parlamento Europeo no establece la compatibilidad de mandatos, de hecho los Diputados nacionales que obtienen escaño en el Parlamento Europeo renuncian al mandato nacional. Por otra parte, determinados sectores de la doctrina han considerado que el establecimiento de la incompatibilidad de mandatos en las legislaciones nacionales no se ajusta a Derecho. El Acta establece unos principios a 
No obstante, el Parlamento Europeo adoptó, el 7 de julio de 1988 una Resolución que invitaba a los Estados miembros a establecer la incompatibilidad entre los mandatos de Diputado nacional y europeo ${ }^{43}$. El objeto perseguido con dicha resolución consistía en potenciar el mandato del parlamentario europeo, de modo que no quedase supeditado a las funciones de los parlamentos nacionales.

Con el fin de asegurar la continuidad de la institución y evitar un vacio del mandato parlamentario, entre el antiguo mandato y la constitución de la nueva Cámara, el artículo 8 RPE, ha previsto que los Diputados permanezcan "en funciones hasta la apertura de la primera sesión del Parlamento siguiente a las elecciones». De esta forma se asegura, hasta la asunción de las competencias parlamentarias por los Diputados electos, la continuidad del mandato decaído. Además, en virtud de lo dispuesto en el artículo 10.3 RPE, en conexión con el artículo 9.1 del Acta de 1976, el Parlamento se reúne sin necesidad de convocatoria el primer martes siguiente a la expiración del plazo de un mes contado a partir de la fecha de las elecciones.

Los Diputados europeos gozan también de las prerrogativas propias de la condición de parlamentario, según quedó establecido en el Protocolo sobre los privilegios y las inmunidades de las Comunidades Europeas ${ }^{44}$. El Capítulo III de dicho documento, integrado por los artículos 8 a 10, está referido a los "miembros del Parlamento Europeo" y en ellos se asegura la libertad de desplazamiento de los Diputados europeos, sin restricción alguna, a la vez que se otorgan facilidades aduaneras y de control de cambios. Y lo que es más destacado, se garantiza la inviolabilidad e inmunidad parlamentaria. El artículo 9 dispone que "los miembros del Parlamento Europeo no podrán ser buscados, detenidos ni procesados por las opiniones o los votos por ellos emitidos en el ejercicio de sus funciones". El artículo 10 concede a los parlamentarios, mientras el Parlamento Europeo esté en período de sesiones, el goce de las inmunidades reconocidas a los miembros del Parlamento de su país $y$, en el territorio de cualquier Estado miembro, "de inmunidad frente a toda medida de detención y de toda actuación judicial». La inmunidad

los que deben acogerse las legislaciones nacionales, mientras no exista una legislación electoral uniforme. Vid. las referencias doctrinales a este tema en ALLUE BUIzA, A.: El Parlamento Europeo: Poder y democracia en las Comunidades Europeas; págs. 77-80.

43 Resolución A2-65/1988.

44 Al Protocolo se remite el artículo 4.2 del Acta de 1976. Éste Protocolo fue adoptado en Bruselas el 8 de abril de 1965, como anexo al Tratado por el que se constituyó un Consejo único y una Comisión única, de la misma fecha. 
ampara también a los Diputados europeos "cuando se dirijan al lugar de reunión del Parlamento Europeo o regresen de éste». Por último, "la inmunidad no podrá invocarse en caso de flagrante delito ni podrá éste obstruir el ejercicio por el Parlamento Europeo de su derecho a suspender la inmunidad de uno de sus miembros".

La normativa comunitaria ha previsto también la solicitud y concesión de un suplicatorio, con el fin de suspender la inmunidad de la que gozan los parlamentarios. El artículo 6 RPE regula la «suspensión de la inmunidad". Los suplicatorios deben dirigirse al Presidente del Parlamento por la autoridad competente de un Estado miembro. La solicitud se deberá comunicar al Pleno y a la Comisión de Asuntos Jurídicos y Mercado Interior, que tiene atribuidas las materias relativas al estatuto de los Diputados, prerrogativas e inmunidades, en virtud de lo dispuesto en el Anexo IV del Reglamento, VI, 12 y 13. Dicha Comisión solicitará a la autoridad que haya iniciado la concesión de suplicatorio, todas las informaciones y aclaraciones necesarias "para formarse un criterio sobre la procedencia de la suspensión de la inmunidad" (art. 6.3 RPE). Además, el Diputado deberá ser oído, si así lo pidiera, y aportar todos los documentos que estime oportunos. Este precepto también permite que el Diputado para el que se haya pedido suplicatorio, pueda ser representado por otro Diputado.

\section{EL SISTEMA ELECTORAL PARA LA ELECCIÓN DE LOS PARLAMENTARIOS EUROPEOS EN LOS ESTADOS DE LA UNIÓN}

Las modalidades de voto establecidas en las legislaciones nacionales para la elección de los miembros del Parlamento Europeo constituyen un elenco diverso, consecuencia de la evolución democrática de cada uno de los Estados miembros. Las listas cerradas y bloqueadas, mayoritarias en los países del sur de Europa, representan una opción exclusiva por una candidatura, mientras que otras modalidades de elección más flexible, invitan al elector a una participación personalizada ${ }^{45}$. El margen de la decisión está en función de la modalidad de

45 Así, hay que considerar «el voto como una expresión de apoyo puede estructurarse como una afirmación exclusiva a favor de un solo candidato o de un solo grupo de candidatos. O puede manifestarse como un apoyo que se distribuye o divide ordenadamente, señalando preferencias entre diferentes candidatos, entre candidatos de un mismo grupo o partido o entre candidatos de distintos grupos. Se suele denominar voto categórico a la primera modalidad y voto preferencial u ordi- 
voto y de otros elementos del sistema, pues las estrategias de los partidos y su influencia en el electorado, condicionan el sentido del voto, de modo que las ventajas del voto preferencial y del panachage 46, como posibilidades de opción personal no son siempre utilizadas por los electores.

El sistema proporcional está establecido en la mayor parte de los Estados miembros, una vez que se superó la dificultad que, durante décadas, encontraron las instituciones europeas para establecer un sistema electoral uniforme ${ }^{47}$. Esto es, la negativa británica a modificar el sistema electoral mayoritario. Pero, al fin, la Ley de 14 de enero de 1999 introdujo en Inglaterra, Escocia y Gales el sistema proporcional D'Hondt a las elecciones de 10 de junio de 1999. Dicha Ley es de aplicación exclusiva a las elecciones al Parlamento Europeo, pues el sistema mayoritario, de honda tradición británica, se mantiene para las elecciones nacionales.

A pesar del paso adelante que ha supuesto el establecimiento en el Reino Unido del sistema D'Hondt, Alemania, Grecia, Irlanda, Italia y Suecia mantienen procedimientos electorales proporcionales distintos. Además en cinco Estados miembros (Alemania, Austria, Francia, Grecia y Suecia) hay establecida una barrera electoral, de modo que es necesario alcanzar determinado porcentaje de votos válidos para entrar en la distribución de escaños. Finalmente, hay que señalar que en Austria, Dinamarca, España, Finlandia, Francia, Grecia, Luxemburgo, Países Bajos, Portugal y Suecia el conjunto del territorio nacional constituye una circunscripción electoral única. Procedemos en primer lugar al estudio del procedimiento electoral en estos países.

En la República Federal de Austria se eligen veintiún Diputados. El elector vota a una lista, pero puede otorgar su voto individualmente a un candidato de dicha lista, de modo que la atribución de escaños, mediante el método D'Hondt a escala nacional, de la media más alta, se hace en función del número de votos por lista ${ }^{48}$. Son los candidatos

nal a la segundan: Vid. VALLÉS, J. M. y BosCH, A.: Sistemas electorales y gobierno representativo, pág. 110 .

46 La expresión panachage significa que el elector puede mezclar candidatos de diferentes listas, de modo que elimine algunos nombres de una lista y los sustituya por candidatos de una lista diferente.

47 Una de las finalidades esenciales del procedimiento electoral uniforme que ha destacado la doctrina es la necesidad de potenciar la existencia de partidos políticos de ámbito europeo. Vid. Arnaldo AlcubiLla, E.; «Elecciones al Parlamento Europeo"; Revista de Derecho Político; núm. 27-28; 1988; pág. 320.

48 El artículo 23.1 de la Constitución austríaca establece que las elecciones al Parlamento Europeo se llevarán a cabo por el sistema proporcional. 
que hayan obtenido el mayor número de votos preferenciales los que resultan electos, siempre que hayan alcanzado un voto preferencial igual al menos al siete por ciento del conjunto de los sufragios otorgados al partido. En la legislación electoral queda por tanto contemplado el voto preferencial ${ }^{49}$. La barrera electoral es del cuatro por ciento, de modo que las listas que no alcancen dicho mínimo son excluidas de la distribución de escaños. El artículo 23.a 2 de la Ley Constitucional establece la existencia de una única circunscripción electoral para la elección de los Diputados al Parlamento Europeo.

El Reino de Dinamarca elige dieciséis representantes en el Parlamento Europeo. El sistema electoral danés es el método D'Hondt, según la fórmula de los divisores. Los electores pueden otorgar su voto a una lista de candidatos o a determinados candidatos de la lista. Existe, por tanto, el voto preferencial y también el panachage, pues se admite la combinación de listas. La presentación de candidaturas está limitada a aquellos partidos que estén representados en el Parlamento nacional (Folketing) o en el Parlamento Europeo, de no ser así los candidatos necesitarán el respaldo de un número mínimo, determinado por ley, de electores. No existe barrera electoral 50.

España tiene una representación de sesenta y cuatro Diputados en el Parlamento Europeo. Son elegidos de acuerdo con la fórmula electoral D'Hondt, establecida para las elecciones nacionales en el artículo 163 de la Ley Orgánica 5/1985 de Régimen Electoral General 51. Para las elecciones al Parlamento Europeo el territorio nacional constituye una única circunscripción electoral y se ha suprimido la barrera electoral del tres por ciento que se establece para las elecciones al Congreso de los Diputados.

La República de Finlandia también utiliza el sistema D’Hondt, según el principio de la media más alta, para elegir a los dieciséis Dipu-

49 Las elecciones al Parlamento Europeo están reguladas por la Ley federal electoral 117/1996 para las elecciones de los representantes de Austria al Parlamento Europeo, aprobada por el Parlamento el 21 de enero de 1996 y modificada por las Leyes federales 201/1996 y 162/1998.

50 La legisłación electoral danesa al Parlamento Europeo está contenida en la Ley de 4 de marzo de 1994, relativa al derecho de sufragio activo y pasivo, con las modificaciones establecidas por las Leyes de 22 de mayo de 1996, de 13 de enero de 1997 y de 4 de mayo de 1998.

51 La legislación electoral española está recogida en la Ley Orgánica 1/1987, de 2 de abril, para la regulación de las elecciones al Parlamento Europeo y en las Leyes Orgánicas 8/1991, de 13 de marzo, y 13/1991, de 30 de marzo, todas ellas incorporadas a la Ley Orgánica 5/1985, de 19 de junio, de Régimen Electoral General. 
tados al Parlamento Europeo 52. La presentación de candidatos y el recuento de votos se hacen a escala nacional. Existe el voto preferencial, de modo que el elector puede establecer sus preferencias por los candidatos incluidos en las listas electorales. No está previsto el panachage. De acuerdo con la legislación finlandesa sólo puede privarse del derecho de sufragio por condena debida a fraude electoral.

La República francesa elige ochenta y siete parlamentarios, mediante el sistema electoral D'Hondt de la media más alta, pero con la peculiaridad de que existe una barrera electoral del cinco por ciento. Además, el modelo de votación, de listas cerradas y bloqueadas, convierten a dicho umbral en un importante corrector del sistema proporcional. Tras la aprobación del Acta de 1976, el Consejo Constitucional estableció unos principios para la representación al Parlamento Europeo en los que debería fundarse la futura ley electoral. La interpretación de estos principios dio lugar a cierta polémica entre la doctrina constitucional francesa, sobre todo en lo que se refiere al alcance del artículo 2 de la Constitución que proclama el principio de indivisibilidad de la República. En todo caso, y a pesar de que la Asamblea francesa reivindicó su potestad legislativa, frente a la declaración del Consejo Constitucional, lo cierto es que la legislación electoral se acomodó a dichos principios 53 . Por ello, el territorio nacional se constituye en una circunscripción única, y los ciudadanos de los Países y Territorios de Ultramar, aunque no forman parte de Unión Europea, participan en las elecciones, para no romper el principio de la indivisibilidad. La legislación electoral permite no sólo el voto por correo, sino también el voto por poderes ${ }^{54}$.

En la República Griega el sistema electoral es proporcional puro a escala nacional. Se eligen veinticinco Diputados en una única circunscripción electoral. Las listas son cerradas y bloqueadas y no está previsto el voto preferencial. El voto es obligatorio para los electores inscritos en el censo electoral, tal como prevé el artículo 51.5 de la Cons-

52 La Ley electoral finlandesa 714/1998, de 2 de octubre, es la vigente y deroga todas las anteriores.

53 Cfr. Arnaldo Alcubilla, E. y otros, El Parlamento Europeo, págs. 247 y 248.

54 Las disposiciones que regulan las elecciones al Parlamento Europeo están básicamente contenidas en la Ley 1977-729, de 7 de julio y en el Decreto 1979160, de 28 de febrero. Francia fue el primer Estado miembro que aprobó la ley electoral que regulaba las elecciones al Parlamento Europeo por sufragio universal directo. Estas disposiciones fueron modificadas por la Ley 1994-104, de 5 de febrero, relativa al ejercicio del derecho de sufragio activo y pasivo de los nacionales de otros Estados miembros de la Unión residentes en Francia. 
titución que dispone: «El ejercicio del derecho de voto es obligatorio. La ley establece cada vez las excepciones y las sanciones penales" 55 . EI porcentaje de votos emitidos necesario para entrar en la distribución de escaños es del tres por ciento, el menor de los umbrales establecidos en los Estados de la Unión para las elecciones al Parlamento Europeo.

En Luxemburgo, cada elector tiene el derecho de emitir seis votos, que es el número de representantes en el Parlamento Europeo, aplicándose una variante del método D'Hondt, la fórmula HagenbachBischoff. El votante puede votar a una lista o seleccionar candidatos de diferentes listas. Esta previsto, por tanto, el panachage. Las listas pueden incluir diferente número de candidatos, pero el máximo es doce. Si se vota globalmente a una lista en la que haya menos de seis candidatos, se asignan a esa lista tantos votos como candidatos incluya. Los escaños se atribuyen de acuerdo con los votos recibidos por cada candidato, cubriéndose las vacantes con los correspondientes candidatos que siguen en cada una de las listas ${ }^{56}$. El voto es obligatorio para los electores inscritos en el censo electoral.

En los Países Bajos, que elige treinta y un Diputados al Parlamento Europeo, el elector puede otorgar su voto a una lista o a un candidato, por lo que es posible modificar el orden de las listas, pero no está permitido el panachage ${ }^{57}$. El sistema electoral de los Paises Bajos permite el voto preferencial, puesto que el elector puede otorgar su voto, bien a una lista bien a un candidato, por lo que es posible modificar el orden de los candidatos en las listas. Está previsto, además del voto por correo, el voto por poderes.

En la República de Portugal el sistema para la elección de los veinticinco Diputados al Parlamento Europeo es el método D’Hondt, en

55 La legislación griega está formada por la Leyes electorales de 20 de julio de 1981 y por la Ley 1443/84, modificadas por la Ley de 22 de marzo de 1994 (relativa al derecho de sufragio activo y pasivo), y por la Ley 2623/98.

56 Tras la aprobación del Acta de 1976, acerca de la elección de los Diputados al Parlamento Europeo mediante sufragio directo, se dicto la Ley electoral Luxemburguesa de 25 de febrero de 1979, completada y modificada por las Leyes de 14 de marzo de 1984 y de 28 de enero de 1994. La Ley de 28 de enero de 1994, regula el derecho de sufragio activo y pasivo de los nacionales de otros Estados miembros, residentes en Luxemburgo, materia sobre la que el Consejo Europeo acordó determinadas medidas de excepción, como ya señalamos anteriormente.

57 La Ley electoral de 28 de enero de 1993, que fue incorporada al Código electoral de 28 de septiembre de 1989, derogó las disposiciones anteriores de la Ley electoral de 28 de enero de 1993. La Ley de 4 de enero de 1994 promulgó las disposiciones relativas al derecho al sufragio activo $y$ pasivo para los ciudadanos nacionales residentes de otros Estados miembros de la Unión Europea. 
una única circunscripción electoral. Las listas son cerradas y no existe el voto preferencial. Las listas electorales, que han de presentarse ante el Tribunal Constitucional, han de incluir el mismo número de candidatos que escaños a proveer, más un número de candidatos suplentes que ha de oscilar entre tres y ocho, aunque no establece umbrales mínimos. El derecho de sufragio activo y pasivo, para los nacionales de otro Estado miembro de la Unión, residentes en Portugal, había sido previsto en la reforma constitucional que llevó a cabo la Ley $1 / 1992$, de 25 de noviembre, cuyo objeto era adecuar la Constitución a las exigencias de la entrada en la Unión Europea. Así, el artículo 15.5 de la Constitución establece: "La Ley podrá atribuir en condiciones de reciprocidad a los ciudadanos de los Estados miembros de la Unión Europea, residentes en Portugal, el derecho de elegir y ser elegidos diputados al Parlamento Europeon 58.

En el Reino de Suecia la elección de los veintidós Diputados en el Parlamento Europeo, se realiza por el sistema proporcional denominado Saint Laguë modificado, según el método de los números impares en que el máximo común divisor se reduce a uno coma cuatro ${ }^{59}$. El elector puede otorgar su voto a una lista o a candidatos individuales, puede atribuir un número de orden distinto del establecido en las listas o si lo desea suprimir nombres. Los candidatos se clasifican según el número de votos preferenciales obtenidos tras agrupar las papeletas que incluyan un voto nominal, teniendo en cuenta que, para la adjudicación de escaños, es necesario que los candidatos hayan alcanzado un voto preferencial de al menos el cinco por ciento del conjunto de sufragios obtenidos por el partido. Los escaños que resten se asignan a los candidatos y a sus suplentes que hayan obtenido mayor puntuación en relación con el número de votos del partido. En caso de que el escaño, iniciada ya la legislatura, quedase vacante será proclamado el suplente. Está autorizado, además del voto por correo y en las representaciones diplomáticas, el voto en los buques en viaje por el extranjero. La barrera electoral establecida es del cuatro por ciento, de tal forma, que los partidos que no alcancen dicho mínimo no serán tenidos en cuenta para la atribución de escaños.

58 La Ley 14/1987, de 29 de abril, regula las elecciones al Parlamento Europeo. La Ley 3/1994, de 9 de marzo, estableció las modalidades del derecho de sufragio activo y pasivo en las elecciones al Parlamento Europeo de los nacionales de otros Estados miembros de la Unión residentes en Portugal.

59 La ley electoral sueca de 1972, que rige las elecciones al Parlamento nacional, ha sido completada, y en parte modificada, por la Ley de 20 de abril de 1995 aplicable a las elecciones al Parlamento Europeo. 
Los Estados que han dividido el territorio nacional en circunscripciones electorales a los efectos de las elecciones al Parlamento Europeo son: Bélgica, Italia, Irlanda y Reino Unido. Procederemos al estudio de sus características, refiriéndonos en último lugar al sistema que se sigue en la República Federal alemana.

Bélgica tiene asignados veinticinco diputados al Parlamento Europeo. La modificación constitucional de 1993 que estableció en el Reino de Bélgica un Estado federal, ha representado que las elecciones de los Diputados al Parlamento Europeo se basen en cuatro circunscripciones electorales. Estas circunscripciones son las siguientes 60: la circunscripción electoral flamenca, que abarca los distritos administrativos de la región flamenca, con excepción del distrito administrativo de Hal-Vilvorde; la circunscripción electoral valona, que incluye los distritos administrativos pertenecientes a la región valona, con excepción de los municipios de la región de lengua alemana; la circunscripción electoral de Bruselas-Hal-Vilvorde, formada por los distritos administrativos del mismo nombre; $y$, la circunscripción electoral germano parlante, que reúne los municipios de la región de lengua alemana.

Existen además en Bélgica los colegios electorales francés, neerlandés y alemán. Los electores inscritos en la lista de la circunscripción de Bruselas-Hal-Vilvorde, pertenecen al colegio electoral francés o neerlandés según la opción elegida. De los veinticinco escaños que representan al pueblo belga en el Parlamento Europeo, catorce corresponden al colegio electoral de lengua neerlandesa, integrado por Flandes y parte de la circunscripción de Bruselas, diez al colegio electoral de lengua francesa, constituido por Valonia y parte de la circunscripción de Bruselas y uno al colegio electoral de habla alemana 61.

En Bélgica el voto es preferencial; cada elector puede otorgar su voto a una lista completa o a un candidato de una lista, aunque no está

60 El país está dividido en cuatro regiones lingüísticas; la región de lengua francesa, la región de lengua neerlandesa, la región bilingüe Bruselas-Capital y la región de lengua alemana. Estas regiones están representadas por la Comunidad flamenca, la Comunidad francófona y la Comunidad gemanófona. En cuanto a las Regiones, a las que hace referencia el artículo $1 .^{\circ}$ de la Constitución son también tres: la Región valona, la Región flamenca y la Región bruselesa: Cfr. ÁlvAREz Vélez, M. I. y Alcón YUSTAS, M. F., Las Constituciones de los Quince Estados de la Unión Europea. Textos y Comentarios, págs. 141 y ss.

61 Las elecciones al Parlamento Europeo están reguladas por la Ley de 23 de marzo de 1989. El 26 de abril de 1994 entró en vigor la ley que regula el sufragio activo y pasivo de los nacionales de otros Estados miembros residentes en Bélgica. La última modificación es la Ley electoral de 5 de abril de 1995. 
permitido el panachage. El artículo 61 de la Constitución dispone que los electores tendrán solamente el derecho a un voto, y el artículo 62 constitucionaliza el voto obligatorio y secreto. Están previstas en la legislación electoral sanciones para los electores que se abstengan.

La República italiana ha de elegir ochenta y siete Diputados europeos, cuya elección se realiza en cinco circunscripciones electorales: la circunscripción del noroeste, formada por las Regiones de Lombardia, Piamonte, Liguria y Valie de Aosta, a la que corresponden veintitrés escaños; la circunscripción del nordeste, integrada por las Regiones de Trentino, Alto Adigio, Venecia-Julia, Friuli y Emilia-Romagna, dieciséis escaños; la circunscripción del centro, que reúne las Regiones de Las Marcas, Umbría, Lacio y Toscana, elige a diecisiete Diputados; la circunscripción del Sur, que agrupa las Regiones de Abruzos, Molise, Apulia, Basilicata, Calabria y Campania, elige veintiún escaños; $y$, la circunscripción de las Islas, que une a Sicilia y Cerdeña, elige diez Diputados.

En Italia el cómputo de los votos y la adjudicación de escaños se hacen en ámbito nacional, estableciéndose en éste ámbito el quórum que determina el número de votos válidos necesarios para la obtención de escaños 62 . Los votos se reparten entre las circunscripciones y los restantes se suman en el ámbito nacional, lo que permite la representación de los partidos minoritarios. Además, si el número de votos que obtiene una lista electoral en una circunscripción es insuficiente para la obtención de un escaño, se transfieren esos votos a la circunscripción en la que la lista del partido de que se trate haya obtenido mayoría de votos. Se establece, por tanto, una transferencia de votos de la que se benefician los partidos, sobre todos los no mayoritarios. En Italia el voto no es obligatorio, pero es considerado un deber cívico 63 .

En la República de Irlanda, los quince representantes en el Parlamento Europeo se eligen por representación proporcional mediante un sistema de voto único transferible, que constituye realmente un sistema electoral diferenciado. Un sistema arraigado en Irlanda, recogido para la elección de los miembros de la Cámara de Representantes, en

62 El quórum se obtiene mediante la división entre el número de votos a escala nacional y número de escaños a elegir.

63 La regulación electoral en Italia está basada en la Ley electoral núm. 18 de 24 de enero de 1979, modificada posteriormente por la Ley núm. 61 de 9 de abril de 1984, la Ley núm. 9 de 18 de enero de 1989, la Ley núm. 128 de 21 de febrero de 1994 (relativo al derecho de sufragio activo y pasivo de los ciudadanos de la Unión) y el Decreto-Ley núm. 408 de 24 de junio de 1994. 
el artículo 16.2.5. de la Constitución. En la papeleta se incluyen los candidatos de todos los partidos e, incluso, de aquellos que se presentan a las elecciones individualmente. El elector señala sus preferencias en la papeleta, junto a los nombres de los candidatos. Los escaños son atribuidos según el modelo Droop-Quota, esto es el número total de votos válidos emitidos más uno, dividido por el número total de escaños a asignar, en este caso quince, más uno. El escaño se atribuye a un candidato cuando obtiene la cuota estipulada en la primera preferencia. Si obtiene mayor número de votos que la cuota, los votos sobrantes se repartirán en las segundas preferencias. Si aún restan votos vuelven a repartirse entre las preferencias siguientes ${ }^{64}$. Este sistema es, en opinión de NOHLEN, uno de los más perfeccionados, pues permite la clasificación de los candidatos y la capacidad para expresar preferencias $e$, incluso, "preferencias alternativas para el caso de que la primera preferencia no consiga imponerse" 65 . No obstante, el reducido tamaño de las circunscripciones hace que se desfigure el principio de proporcionalidad, de modo que se ha considerado un sistema próximo al sistema mayoritario, o "cuasi proporcional». La tendencia a establecer circunscripciones pequeñas en Irlanda tiene el límite establecido en la Constitución, que no permite que se elijan menos de tres escaños por circunscripción 66 . Para las elecciones europeas, los quince Diputados que corresponden a Irlanda, se distribuyen en cuatro circunscripciones: Dublín, Munster y Leinster, eligen cada una cuatro y Connacht, en Ulster, a tres diputados.

También Reino Unido, que elige ochenta y siete diputados, ha dividido el territorio nacional en varias circunscripciones. La European Assembly Elections Act fue aprobada el 4 de mayo de 1978, tras un polémico debate, no sólo relativo a elementos concretos del sistema electoral, sino debido a las dudas acerca de la conveniencia de la participación en las elecciones al Parlamento Europeo por sufragio universal directo. Posteriormente, esta legislación fue modificada en

64 Una exposición detallada de la fórmula para la atribución de escaños en el sistema de método único transferible (single transferable vote), puede encontrase en: NoHLEN, D., Los sistemas electorales del mundo, pág. 310-312.

65 NOHLEN, D., Sistemas electorales y partidos políticos, pág. 253.

66 Artículo 16.2.6. de la Constitución irlandesa. En Irlanda las elecciones al Parlamento Europeo se regulan en la European Assembly Election Act de 1977, la European Assembly Election Act de 1979, la European Assembly Election Act de 1984, la Electoral Amendment Act de 1986, la Electoral Act de 1992 y la European Parliament Election Acts de 1993. Además la European Parliament Elections Regulations de 1994, regula el derecho de sufragio activo y pasivo de los ciudadanos de la Unión. Las últimas modificaciones corresponden a las Leyes electorales de 1997 y 1998. 
numerosas ocasiones: por la European Assembly Elections Act de 1981, las Representation of People Acts, de 1983 y 1985, los reglamentos de 1986, relativos a las elecciones en Escocia e Irlanda del Norte, y por la European Parlamentary Act de 1993. En cuanto a la Directiva relativa al derecho al ejercicio del sufragio activo y pasivo de los ciudadanos de la Unión residentes en un Estado miembro distinto del Estado de origen, fue desarrollada por la European Parliament Regulation de 1994. Y, por último, como ya señalamos anteriormente, la ley de 14 de enero de 1999 aplicó por primera vez en Reino Unido un sistema electoral proporcional, sustituyendo al sistema mayoritario, sobre el recuento de listas regionales cerradas en once circunscripciones. De los escaños atribuidos al Reino Unido, Inglaterra, Escocia y País de Gales eligen ochenta y cuatro Diputados, distribuidos en las siguientes regiones-circunscripciones electorales: Eastern, ocho escaños; East Midlands, seis escaños; Londres, diez escaños; North-East England, cuatro escaños; North West England, diez escaños; South East England, once escaños; South West England, siete escaños; West Midlands, ocho escaños; Yorkshire y Humbreside, siete escaños; Escocia, ocho escaños; y País de Gales, cinco escaños. Irlanda del Norte dispone de tres escaños, que se eligen en una única circunscripción. El sistema electoral de Irlanda del Norte es, como en la República de Irlanda, un sistema de voto único transferible 67.

Finalmente, en la República Federal alemana la elección de los noventa y nueve Diputados se realiza de acuerdo con el sistema HareNiemeyer, que favorece ligeramente a los partidos minoritarios y que sustituyó al sistema D'Hondt, pues así lo acordó en 1985 el Bundestag. La fórmula Hare-Niemeyer adscribe los escaños en dos etapas. En la primera los escaños se distribuyen entre las diferentes listas presentadas por los partidos en cada Land, coaligadas con las del mismo partido en ámbito federal. Así se obtiene el número de escaños que corresponde a cada partido. En una segunda fase el número de escaños ya atribuidos es repartido entre las listas de los diferentes partidos, siempre que hayan superado el umbral del cinco por ciento. Esta es la barrera electoral establecida, un porcentaje alto que el Tribunal Constitucional alemán declaró compatible con el principio de representación proporcional. Los partidos políticos tienen la posibilidad de presentar listas de candidatos en el ámbito del Land o a escala nacional, de tal forma que si un partido presenta listas en un Land, todos los escaños

67 En Reino Unido se permite el sufragio activo y pasivo para la elección de los Diputados al Parlamento Europeo a los miembros de la Cámara de los Lores, lo que no está permitido en las elecciones nacionales. 
que gane se distribuyen entre las listas nacionales ${ }^{68}$, de modo que la atribución de escaños se realiza en el ámbito federal. Las formaciones políticas que no cuenten con un mínimo de cinco escaños en el Bundestag o en la dieta de un Land, deberán reunir cuatro mil firmas acreditadas para presentar una lista federal o dos mil, si se pretende presentar la candidatura en un Land.

\section{BIBLIOGRAFÍA CITADA}

Allue Buiza, A., El Parlamento Europeo: Poder y Democracia en las Comunidades Europeas, Secretariado de Publicaciones de la Universidad, Valladolid, 1990.

Álvarez Vélez, M. I. y Alcón Yustas, M. F., Las Constituciones de los Quince Estados de la Unión Europea. Textos y Comentarios; Dykinson, Madrid, 1996.

Arnaldo Alcubilla, E. y otros; El Parlamento Europeo, Acción Informativa del Parlamento Europeo (Partida 7308), Madrid, 1987.

Arnaldo Alcubilla, E., "Elecciones al Parlamento Europeo"; Revista de Derecho Político; núm. 27-28; Madrid, 1988.

BarAs, M. y Botella, J., El sistema electoral, Tecnos, Madrid, 1996.

Elecciones al Parlamento Europeo (Documentación preparada para la tramitación del Proyecto de Ley de modificación de la Ley Orgánica 5/1985, de 19 de junio, de Régimen Electoral General, para la regulación de las Elecciones al Parlamento Europeol; BOCG-Congreso, Serie A, núm. 23, de 4 de febrero de 1987; Documentación núm. 54, febrero 1987.

Gasoliba I Bohm, C., El Parlamento Europeo, Tibidabo, Barcelona, 1986.

Lavilla RuBiRa, J. J., "La posición institucional del Parlamento Europeo", Revista de las Cortes Generales, núm. 9, Madrid, 1986.

MANGAS MARTín, A. y LIÑÁN Nogueras, D.J., Instituciones y Derecho de la Unión Europea, Mc Graw Hill, Madrid, 1999.

MANGAS MARTín, A., "Estudio preliminar», en Tratado de la Unión Europea, Tratados Constitutivos de las Comunidades Europeas, y otros actos básicos de Derecho Comunitario, Tecnos, Madrid, 1992.

NOHLEN, D., Sistemas electorales del mundo, CEC, Madrid, 1981.

NoHLEN, D., Sistemas electorales y partidos políticos, Fondo de Cultura Económica, México, 1998.

68 La Ley electoral alemana a los representantes al Parlamento Europeo de 16 de junio de 1978, fruto de un acuerdo entre los intereses del Bund y de los Landër, fue modificada el 11 de noviembre de 1993. Vid. GASOLIBA I BoHM, C. A.; El Parlamento Europeo; pág. 31. También las elecciones al Parlamento Europeo están reguladas por la Ley de 13 de marzo de 1994, relativa al derecho de sufragio activo y pasivo de los ciudadanos de la Unión Europea. La última modificación de la Ley electoral es de 18 de junio de 1997. 
RodríguEz, A., "La Unión Europea: organización institucional y fuentes del Derecho Comunitarion, en, Balaguer Callejón, F., (coord.), Derecho Constitucional, Vol. I, Tecnos, Madrid, 1999.

Santaolalla López, F., Elección en España del Parlamento Europeo, Civitas, Madrid, 1987.

TruYol Y SERRA, A., La integración europea. Idea y realidad, Tecnos, Madrid, 1972.

VALLÉS J, M. y Bosch, A., Sistemas electorales y gobierno representativo, Ariel, Barcelona, 1997. 